\title{
Aspectos intermediales de la enseñanza audiovisual. Un abordaje transversal, entre el cine y los nuevos medios
}

\section{Russo, Eduardo A. [ver currículum del autor, docente de la Facultad de Diseño y Comunicación]}

\section{Resumen:}

El artículo propone una revisión y apropiación del concepto de intermedialidad, elaborado de forma colectiva en el marco de la reflexión sobre prácticas artísticas experimentales, el análisis y teoría del discurso, y la teoría de los medios audiovisuales. Conjugando distintas expresiones contemporáneas sobre lo intermedial, particularmente elaboradas en su vinculación con las teorías del cine y los new media, se examina su despliegue en los discursos y soportes, considerando la creación de imágenes en sus aspectos híbridos y migratorios como una actividad modulada tanto entre distintos medios como en el seno de cada estructura medial.

\section{Cuadernos del Centro de Estudios de Diseño y Comunicación Nº 66}

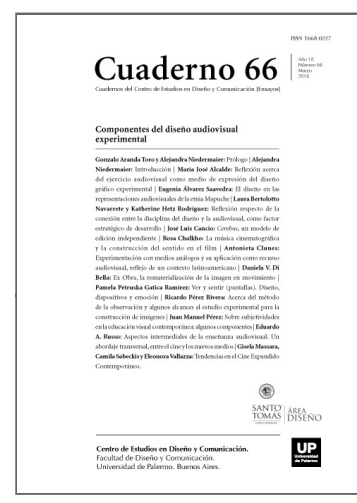

ISSN: 1668-0227

Componentes del

diseño audiovisual

experimental

Año XVIII, Marzo 2018, Buenos Aires, Argentina | 196 páginas

descargar PDF

ver índice de la publicación

Ver todos los libros de la publicación

compartir en Facebook

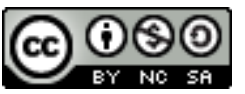

Esta obra está bajo una Licencia Creative Commons Atribución-NoComercialCompartirlgual 4.0 Internacional

Para apreciar los aspectos heurísticos y prácticos de esta aproximación en su potencial didáctico en un ámbito en transformación y expansión, el artículo estudia como caso sintomático de dicha modalidad de creación a la figura y el mito de Frankenstein, a lo largo de su recorrido intermedial.

Palabras clave:

Cine - Intermedialidad - Audiovisual - Enseñanza - Experimental

(*) Investigador, teórico y crítico de cine y artes audiovisuales. Dirige el Doctorado en Artes de la Universidad Nacional de La Plata, Argentina. Es profesor de la Universidad de Palermo desde 1992.

Introducción: ante la ansiedad del cambio

Uno de los factores cruciales a la hora de pensar desde los contenidos de una asignatura hasta un plan de estudios de una carrera universitaria orientada a la formación en el campo audiovisual contemporáneo, radica en 
la complejidad creciente de este ámbito. El espacio que nos ocupa se encuentra caracterizado por la convivencia de medios tradicionales y nuevos medios, la aparición de disponibilidades técnicas inéditas y altamente disruptivas, nuevos usos y prácticas a menudo imprevistos, la creciente porosidad entre instituciones y formas mediales que durante muchas décadas habían cultivado una identidad no exenta de orgullo por su autonomía, y fenómenos que desafían las actividades tradicionales, tanto en el polo de la producción como en la recepción.

El presente entorno es de difícil diagnóstico y muy poco apto para las profecías, ni siquiera a corto plazo, a pesar de que los discursos promocionales de los voceros del mercado no dejen de emitirlas bajo las consabidas premisas:

a. En el terreno de los medios, el advenimiento de lo nuevo viene a desplazar y dejar obsoleto a lo viejo.

b. Estamos inmersos en una carrera donde es imperioso estar al día. Debemos desestimar lo pasado, incluso reciente, por vetusto y concentrarnos en el presente que marca tendencias al futuro posible.

Si bien es cierto que la lógica del cambio rige al universo de los medios, entre ellos los audiovisuales, es importante advertir que aunque la aceleración de las transformaciones es un dato irrefutable del presente, no se trata de un punto que indique una diferencia cualitativa respecto de situaciones anteriores. De hecho, la sociedad y cultura masas nacientes de fines del siglo XIX, la sociedad mediada de los inicios del siglo XX y la ya hipermediada del fin de la centuria sostuvieron al cambio continuo, y aún a las crisis periódicas, como uno de sus motores fundamentales. La Inglaterra victoriana era vivida por sus contemporáneos, según innumerables testimonios, como víctima de una aceleración intolerable. El cambio acentuado solía provocar frecuentes episodios de ansiedad ante un presente que se desmarcaba del pasado inmediato y que prometía un futuro con mucho de impredecible. Lo único predecible, ya para entonces, es que ese futuro prometía cambios radicales en relación al tiempo presente. Una experiencia de perpetuo vértigo en los más diversos órdenes de la vida.

El fenómeno ha crecido fundamentalmente en lo cuantitativo. Lo que vivimos hoy es más intrincado y más veloz, pero no consiste en un dato radicalmente nuevo. Nos mueve en este artículo la premisa que formulase Siegfried Zielinski, uno de los fundadores de lo que da en llamarse arqueología de los medios. Un campo de estudios que traza conexiones entre episodios a veces distanciados históricamente, pero que permite advertir la persistencia y complejidad de nuestra relación con los medios. Esta arqueología, de modo inverso a lo que podría pensarse, manifiesta un constante interés en las nuevas condiciones mediales y técnicas, en sentido amplio, con las que vivimos en el mundo contemporáneo. Acaso sea algo extensa la siguiente cita, pero es conveniente hacerla comparecer en su desarrollo, dado su carácter metodológico, e incluso su tono de manifiesto:

De hecho, existe algo así como una actualidad de lo pasado. Sin embargo, si hemos de comprender la actualidad de la historia no solamente allí donde es correcto verla como carga y obligación, sino también allí donde vale la pena dejarla desplegarse como atracción especial, entonces necesitamos cambiar esa actitud que logra solo hallar lo viejo en lo nuevo. La historia vista en esta perspectiva es en el fondo una promesa de conservación, es la celebración del progreso constante bajo el signo de la humanidad. Ya todo estuvo alguna vez presente, sólo que en forma menos elaborada. Solo tienen que observar con mayor detenimiento. Los siglos son para pulir y perfeccionar las grandes ideas arcaicas. Esta es una mala pedagogía. Es aburrida e inhibe el incansable y necesario trabajo de transformación. 
La inversión, en el sentido de un desplazamiento intencional, requiere ser pensada y probada de manera experimental: no buscar lo viejo, lo ya existente desde siempre, en lo nuevo, sino descubrir cosas nuevas, sorprendentes, en lo viejo. (Zielinski, 2011, p. 4)

Proponemos, en el curso de este artículo, indagar algunos ángulos de un concepto que cuenta con un largo recorrido en el último medio siglo, que inició precisamente cuando los classic media y los new media comenzaron a reconfigurar el entorno mediático en un sentido global. Se trata del concepto de intermedialidad, cuyas implicancias, de ser atendidas, afectan no solamente el modo de pensar los medios y nuestra relación con ellos, sino las formas en que operamos en el ámbito y, por qué no, la misma estructura que dichos medios en transformación producen.

Intermedialidad: genealogía parcial de un concepto múltiple

No intentaremos aquí buscar un origen prístino y singular de un concepto que se ha caracterizado por una cualidad que apunta a lo contrario: ha surgido de manera más o menos contemporánea en distintos ámbitos. El término ha sido utilizado prolíficamente en el ámbito de los estudios literarios y teatrales, en distintas teorías de los medios masivos y los new media y en el pensamiento sobre el cine, entre otros campos. Debemos una de las apariciones tempranas de la intermedialidad a Dick Higgins, un artista múltiple que incursionó en la composición musical, la poesía y las artes gráficas. Higgins la pensó desde un espacio particular en el que instalaba su práctica, y la denominó intermedia.

Podría considerarse que realmente necesitaba esta perspectiva, impulsado por las diversas áreas de su actividad creativa. Higgins pertenecía al célebre colectivo Fluxus, cuya producción se ha caracterizado por ser difícilmente reductible al uso de un medio o a unos medios particulares. Por lo contrario, una intervención Fluxus por lo general cuestionaba y redefinía los límites de un medio establecido, circulaba de un medio a otro, no sólo transformando la obra, sino también operando en la metamorfosis de cada medio y los sistemas en los que podría desplegar su acción. Inscripto en el espíritu de las tardovanguardias de los años sesenta, el artista elaboró su "Statement on Intermedia" en 1966, sentando las bases de una forma de creación artística que intentaba no sustentarse en el ejercicio de un medio, sino atravesar varios de ellos y eventualmente crear nuevas formas en ese mismo movimiento. Señalaba el manifiesto:

Durante aproximadamente la última década, los artistas han cambiado sus medios para adaptarse a esta situación, al punto en que los medios se han quebrado en sus formas tradicionales, y se han convertido en meros puntos de referencia puristas. La idea ha emergido como si fuera por combustión espontánea a través del mundo entero, y esos puntos son arbitrarios y solamente útiles como herramientas críticas al señalar que tal o cual trabajo es básicamente musical, pero también es poesía. Esto es el acercamiento intermedial: el enfatizar la relación dialéctica entre medios. Un compositor es un hombre muerto a menos que componga para todos los medios, y para su mundo. (Higgins, 1996, p. 728)

En un registro académico también resulta fundamental la acepción que otorga a lo intermedial un teórico de los medios como Jürgen Ernst Muller, quien ha desarrollado una concepción de lo intermedial como intento de superación de la conocida noción de intertextualidad debida, entre otros, a Julia Kristeva. Esta opción implica un descentramiento de la atención predominante en las categorías textuales, para orientarse a la consideración de las formas mediáticas, las materialidades y los juegos que operan en las operaciones semióticas complejas, que 
incumben al trabajo de varios medios en complementariedad con vistas a una producción que cobra entidad más allá de sus delimitaciones particulares, atravesándolas: intermedialidad es, para Muller, el estudio de la función de las interacciones mediáticas sobre la producción de sentido. Y precisa sobre su necesidad:

Para mí y para algunos de mis colegas, el punto de partida para esta nueva aproximación fue a necesidad de tomar en cuenta un hecho irrefutable: se ha convertido en algo simplemente inaceptable ver a los medios como mónadas aisladas. Las familiares teorías y las historias de los medios no son ya capaces de cumplir con las expectativas de la investigación. Se ha hecho necesario volver la atención hacia los fenómenos audiovisuales contemporáneos y sus relaciones mutuas, y estudiar sus complejas interacciones. (Muller, 2010, p. 8)

Obsérvense las líneas finales de la cita, donde lo audiovisual hace su entrada en escena como un elemento particularmente removedor de las fronteras entre medios, cuestionador de esas delimitaciones que la sociología y la teoría de la comunicación ha llamado tradicionalmente como "definición" de un medio: un lugar para cada uno y cada uno en su lugar. Compitiendo, negociando, eventualmente batallando entre sí, pero asentándose y evolucionando en un territorio asignado o, llegado el caso, invadiendo al vecino. Tiempo pasado de la teoría: acaso esa definición haya estado más fundada en las presunciones de los teóricos que en la realidad del devenir de los medios.

Ante las actuales transformaciones de las prácticas de pantalla, la enseñanza de las artes y el diseño audiovisual hoy se enfrenta a un desafío crucial. Distintos procesos de convergencia e hibridación mediática obligan a comprender cómo cada medio ha participado, durante todo su itinerario histórico, de un entramado en el que experiencias y contenidos fluyen de un territorio a otro. De ese modo, presuntas especificidades e identidades que durante mucho tiempo de pensaron como fuertemente definidas, se ven severamente cuestionadas. Por otra parte, la búsqueda o la transmisión de lenguajes altamente codificados o estabilizados se ve reemplazada por la necesidad de atender a formas, expresiones e imágenes que dan cuenta de un estado de tránsito.

Lejos de ser criaturas nacidas en estado de pureza, tecnologías, espectáculos y prácticas audiovisuales como las del cine, la televisión y los nuevos medios comparten cierta matriz abierta a lo disímil, a zonas de conflicto interior, a la hibridación fundante. Son compuestos por fragmentos de cuerpos de distinta procedencia y animados por una energía tan extraña como efectiva. El concepto de intermedialidad, generado simultáneamente en el marco de las humanidades, las ciencias sociales y las prácticas artísticas deja dilucidar, incluso con las diferencias de sus acepciones y recorridos heterogéneos, algunos aspectos decisivos de esta situación y dar pautas de acción en el terreno de la didáctica audiovisual. Más que un concepto pasible de una definición breve y con aspiraciones de esclarecimiento definitivo, la intermedialidad involucra un movimiento investigativo que debe aceptar algunas incertidumbres en juego. Podrá argüirse que la conexión entre las ideas perfiladas en un plan estético-político por Higgins se extraen de un campo que no pertenece al mismo suelo epistemológico que los desarrollos académicos de un Muller, pero al considerar la amplitud y variedad del largo debate sobre este concepto, el heterogéneo entramado de su elaboración colectiva resulta un dato fundamental, más enriquecedor que una presunta afinidad o familiaridad de origen. En el desarrollo del concepto ya activo en los estudios audiovisuales, un reciente volumen que compila resultados parciales advierte sobre esta enmarañada configuración, destacando su potencial, radicado en su misma condición de concepto polimorfo: 
(La intermedialidad es) una aproximación diferente, en el dominio de los estudios cinematográficos y culturales. Una aproximación que permite pensar la dinámica entre las prácticas significantes dentro de una nueva perspectiva y que, al mismo tiempo, invita a revisar la historia del cine y de otras artes, especialmente en relación a la exigencia de especificidad, con sus líneas de demarcación entre una práctica y otra, así como entre cada práctica y la vida. Una aproximación que propone, de entrada, nuevas cuestiones, y no, como frecuentemente es el caso, que otorga respuestas nuevas a cuestiones viejas. (Mariniello, 2000, p. 9)

Resulta imposible pretender en el limitado marco de nuestro artículo un panorama abarcativo de la complejidad que lo intermedial comporta desde su surgimiento heterogéneo y simultáneo en el marco de distintas disciplinas científicas y artísticas. Por sus mismas características de atención a lo intersticial, al cuestionamiento de fronteras preestablecidas, la puesta en consideración de lo intermedial ha desafiado no pocas compartimentaciones: así como resalta e indaga formaciones que se desenvuelven cuestionando las pretensiones de especificidad e identidad mediáticas que muchas veces operaron como verdaderos bastiones, también posee la facultad de corroer fronteras en cuando a disciplinas de conocimiento. En años recientes se ha intentado en varias oportunidades no tanto los intentos de definición taxativos como la apreciación de lo intermedial como un campo no exento de interrogantes y oscuridades. Destacamos entre estos balances y plataformas para su reconsideración en un ámbito rigurosamente actual la reciente e informada reseña elaborada por Agnes Petho (2010, pp. 39-72) sobre el alto impacto y las variadas discusiones que esta noción ha suscitado en el campo de los estudios audiovisuales y las teorías de los nuevos medios.

En lo que a nuestro objetivo respecta, munidos de los referentes ya consignados que dan muestra de las diversidades y algunos de los matices cruciales en juego, es posible ya proceder a cierta operativización de este concepto en el abordaje de un caso específico. No se trata de exactamente de un caso particular, sino de uno cuyo protagonismo parece apuntar a cierto núcleo significativo del ámbito que nos ocupa. Originado en la literatura, en plena eclosión del movimiento Romántico y proveniente de la creación de una joven de menos de veinte años, se expandió rápidamente de un modo que podría calificarse como intermedial y se convertiría en una de las figuras más reconocibles e inquietantes de la imaginación de dos siglos enteros. Daría origen a un mito y a una iconografía particular, instalada tanto en una red medial crecientemente compleja como en el interior de cada uno de sus lectores y espectadores. Se trata, por cierto, de la figura y el mito de Frankenstein: más allá de sus tradicionales consideraciones como obra literaria, creación cinematográfica y responsable de un cúmulo de adaptaciones a la escena teatral que ya en los años ochenta del siglo pasado alcanzaban casi el centenar de versiones dramáticas diferentes, a lo largo de todo el mundo (Forry, 1982), examinaremos algunas de las complejas determinaciones intermediales que el temerario científico Dr. Frankenstein y su criatura han vivido, desde sus primeros pasos en el imaginario colectivo, hasta la actualidad. Elegimos este caso, por otra parte, haciendo lugar a la conocida intelección del teórico Noël Burch, quien en un influyente estudio sobre el cine de los comienzos y los acontecimientos que llevaron a la irrupción del fenómeno a lo largo del siglo XIX, no dudó en pensar al cine como un fenómeno íntimamente ligado a la figura del Dr. Frankenstein y su perturbadora creación. Para autor de El tragaluz del infinito, la genealogía del cine se inscribe en el gran sueño frankensteiniano del siglo XIX, esta es, una forma tecnológica de recreación de la vida orientada por la fantasía última: la supresión de la muerte (Burch, 1989, pp. 38-39). Resulta pertinente, así, seguir en los pasajes que siguen la enseñanza del longevo trayecto de este fantasma

Frankenstein y su criatura: algunos avatares intermediales 
Recorramos el itinerario histórico y mediático del creador y la criatura frankensteiniana en su decurso de dos siglos a través de distintos territorios mediales. En la segunda centuria su presencia audiovisual ha sido determinante en su inscripción dentro de un imaginario colectivo donde aún conserva intacto, a pesar de su longevidad, su poder de fascinación e inquietud. La perspectiva intermedial para abordar este recorrido ilumina aspectos inéditos del mito, a la vez que puede brindar elementos que contacten tradición e innovación en la imaginación en pantalla, reconocimiento de una matriz histórica y los potenciales de recreación presente para reimaginarlo en proyectos futuros.

La novela de Mary Shelley, Frankenstein o el moderno Prometeo, fue publicada en su primera versión en forma anónima hacia 1818. No fueron pocos los que no creyeron en la autoría de la joven escritora, prefiriendo pensarla como proveniente de la pluma de su marido, el poeta Percy Bysshe Shelley. El relato resultó tan fascinante como escabroso para los estándares de la época, y la novela pronto expandió su influjo: entre sus efectos se hallan tempranas adaptaciones a la escena. En 1823 se escribió la primera adaptación teatral de la novela. Pressumption: The Fate of Frankenstein, obra dramática de Richard Brinsley Peake. Pronto fue un suceso y se interpretó exitosamente durante 37 semanas seguidas, volviendo a cartel periódicamente hasta 1850. El comediante T. P. Cooke fue la criatura en Pressumption y la encarnó 350 veces. Su interpretación instalaba al monstruo como una entidad medio adánica, medio luciferina, apoyada en su físico imponente que hacía empequeñecer al Dr. Frankenstein. Cabe recordar que en el relato novelesco de Mary Shelley la calificación como monstruo cede permanentemente a la designación como el demonio, y en esas resonancias basó su composición. De piel azulada y privado del habla, sentaría las bases de una iconografía que pasaría al cine con la celebérrima composición de Boris Karloff. Pero no había en su presencia signos de monstruosidad física, sino una plenitud que apuntaba más bien a una vida artificial desmesurada, casi sobrehumana. En los grabados de la folletería publicitaria de la obra se lo ve imponiendo su tamaño y su presencia apolínea ante un amilanado Frankenstein.

En otra adaptación de 1826, escrita por Henry M. Milner, el monstruo fue interpretado por Richard John O. Smith. En la tarjeta promocional de la pieza, titulada sucintamente Frankenstein, se observa un aspecto humano, con rizos y vestimenta de clásicas reminiscencias, si bien con expresión exasperada, que podría calificarse como demoníaca. Estas presencias escénicas, de especial repercusión, parecen haber influenciado una muy sugestiva ilustración que abre la segunda edición de Frankenstein en 1831, que llevó a la imprenta la que ya era una tercera versión de la novela, con un nuevo prólogo de la autora. En dicha imagen ubicada en la portada interior del volumen, el creador se ve enfrentado a su criatura recién nacida de modo artificial y plenamente adulta. La posición recogida en el piso, no deja lugar a dudas, se trata del instante del nacimiento del monstruo. Sin ser deforme, su postura revela un descalabro interior: se trata del instante en que la criatura cobra conciencia de sí y su creador se aparta espantado ante el resultado de sus esfuerzos. El horror queda graficado por un esqueleto a sus pies. En lo que a la criatura respecta, la desnudez no deja apreciar signos de monstruosidad, y el horror radica en su expresión desesperada.

A mitad del siglo XIX, como bien lo ha remarcado Jean-Jacques Lecercle en Frankenstein: mito y filosofía, la figura frankensteiniana es evocada para mentar tanto el traspaso de límites del científico como la presencia de la criatura abominable. Especialmente esta última se convierte, para la imaginación conservadora, en imagen de toda presencia política no dominable y crecientemente inquietante por su capacidad destructiva, sus poderes fuera de control y posiblemente orientados por una oscura, incógnita malignidad constitutiva. En la imaginación tory de la época, desde el costado conservador se califica como monstruo de Frankenstein al proletariado, a las 
ciudades progresivamente hacinadas, a la amenaza revolucionaria (Lecercle, 2001). Un claro ejemplo de esta consideración la otorga un agresivo dibujo de Sir John Tenniel, el mismo que ilustrase los relatos de Alicia publicados por Lewis Carroll, publicado en la célebre revista Punch. En el número del 20 de mayo de 1882 se aprecia una caricatura que muestra el deambular de una horrenda figura, armada de un cuchillo sangrante. Se titula The Irish Frankenstein, el Frankenstein irlandés. Resulta interesante no solamente por la estrategia de concentrar en una imagen monstruosa y con finalidad propagandística un colectivo aborrecido y destinado al humor sangriento para deleite del inglés medio, sino porque el lugar protagónico que se le otorga al monstruo ilustrado. El epígrafe recurre a una cita textual de la novela de Shelley, donde refería al "funesto monstruo, manchado de sangre". Pequeño y al fondo se ve a un atildado caballero que nada puede hacer para detener al asesino: se trata del político nacionalista irlandés Charles Stuart Parnell, y el monstruo condensa el aborrecido Movimiento Feniano, a quien se le atribuían los asesinatos de Phoenix Park, en Dublin, un doble crimen político cometido con cuchillo, que llevó a la muerte a dos personalidades ligadas al dominio británico. La relación de ambas figuras y el epígrafe ya muestran hasta qué punto se verifica el tránsito del nombre y la atención del hombre común desde el científico transgresor hacia la criatura. El Frankenstein irlandés del título parece referirse más al ser deforme que al alelado y empequeñecido líder político.

Al término de la centuria, intermedialidad mediante, literatura novelesca, teatro popular, gráfica publicitaria, periodismo, propaganda y humor político asentaron, en forma conjunta y con recurrencias de uno a otro medio, de uno a otro soporte, en discursos entre la ficción y la metáfora propicia en las crónicas sobre la realidad, en las letras, la imagen gráfica y la presencia escénica, una poderosa presencia y un inmediato reconocimiento a Frankenstein y lo frankensteiniano. Cabría agregar que la imagen se había impuesto al relato: era posible que el lector o el observador no conociera las peripecias de la novela de Mary Shelley o la trama de sus adaptaciones dramáticas, pero la figura de Frankenstein y su mundo, muy particularmente del monstruo innominado pero tan portador del apellido como su creador, ya se cernía sobre la imaginación de las masas.

A comienzos del siglo siguiente, el cine integró sus propias imágenes y relatos a la saga. La primera versión en pantalla fue producida por los estudios Edison y filmada en 1910 por J. Searle Dawley. La criatura fue en este cortometraje interpretada por Charles Ogle, quien compuso un ser grotesco, de articulaciones descoyuntadas y aspecto alucinado, cuyo peinado y vestuario remedaban un enorme y peligroso bufón que no obstante mantiene una inquietante relación de doppelgänger (el doble persecutorio y mortífero de la tradición romántica) con su creador. En una torsión llamativa, hasta el monstruo se horripilaba de su aspecto al ser enfrentado a un espejo.

Redescubierta recién en los años setenta, hoy posible acceder sin dificultad, al ser sus imágenes de dominio público, a esta primera incursión cinematográfica en el mundo frankensteiniano en plataformas como YouTube. Otras dos adaptaciones de la historia de Frankenstein a la pantalla se sucedieron en el cine mudo, ambas hasta hoy perdidas. La primera, de la que hasta hace pocos años no se conocían más que alguna información escrita sobre su producción y recepción, fue Life Without Soul (Joseph W. Smiley, 1915). Aunque no se conserva ni un fragmento de este film independiente de 70 minutos, cabe resaltar que recientemente al escaso bagaje de datos parafílmicos preservados sobre esa película perdida se ha agregado una curiosa foto fija -presumiblemente del rodaje- que presenta al monstruo, evidentemente cercano a cierta iconografía proveniente del mito rousseauniano del "buen salvaje". La criatura se encuentra en un paisaje agreste a orillas de un lago, posiblemente a punto de alimentarse con un pez que ella misma ha extraído del agua. Esa misma fotografía fue el punto de partida para ilustrar al monstruo en el único afiche que se conserva del estreno de ese largometraje, que en ningún momento menciona el nombre de Frankenstein en una típica maniobra para evitar el pago de 
derechos de autor. Si es un monstruo, esta vida sin alma seguramente lo sería por sus actos o su condición de maldita moral, porque a lo sumo se ve como un ser humano convencional, a lo sumo dotado de un físico corpulento, tal como lo sugería la novela y lo había desarrollado la tradición escénica.

Igual resolución adopta para la presentificación de la criatura la versión italiana, II mostro di Frankenstein ( Eugenio Testa, 1920) de la que se conserva considerable información de prensa y publicitaria, más algunas fotografías provenientes de la película perdida. Existen discrepancias sobre cómo aparecía el monstruo que aquí dominaba hasta el mismo título, pero la fuerza física era una constante, tanto como para convocar entre los intérpretes al célebre Luciano Albertini, mas conocido como Sansone, que en este caso interpretando a un aguerrido barón se anima a enfrentarse físicamente a la criatura que encarnaba el actor especialista en villanos Umberto Guarracino.

No nos extenderemos mucho en la insoslayable Frankenstein (James Whale, 1931) dado que es de esos films que parecen pertenecer y ser familiares a cada espectador, incluso a quienes no se han sentado a seguir su historia. La figura de la criatura que encarnó Boris Karloff y que impregnó todo el resto de la vida de este multifacético actor inglés, se debe tanto a su talento como al insólito conjunto de prótesis y maquillaje diseñado por Jack Peirce, que obligaba a sesiones de largas horas preparatorias en el camarín para cada jornada de rodaje. El éxito de Frankenstein llevó a la larga presencia en pantalla, a través de numerosas secuelas que se prolongarían por varias décadas, incluyendo todo tipo de derivaciones y no pocas parodias. El aspecto del monstruo pronto accedería a todo tipo de réplicas incluyendo máscaras de Halloween y trascendería fronteras, para convertirse en una figura señera del selecto panteón de creaciones cinematográficas compartidas por las más diversas culturas y públicos. En esa serie de presencias, un punto destacado en lo que a intermedialidad respecta lo brinda La novia de Frankenstein (Bride of Frankenstein, James Whale, 1935).

En un breve aunque brillante estudio sobre este curioso film, que parte de la tradición frankensteinana para ingresar en un tan extravagante como seductor universo de insólitas referencias en concurso, Alberto Manguel ha destacado el entrecruzamiento intermedial que se produce no solamente en la progresiva y problemática humanización del monstruo, sino cómo el diseño de la novia del título manifiesta coordenadas iconográficas e implicancias formales que relacionan a la imaginación del film hollywoodense, un tanto inesperada, con algunas experiencias extremas en cuanto a los límites de la representación de lo femenino en experiencias de vanguardia como la fotografía de Man Ray o la obra plástica de Marcel Duchamp o Max Ernst. Cine, foto, pintura, collage, concurrieron a la presentificación de otra criatura inolvidable. (Manguel, 1997, pp. 55-62)

No pretendemos aquí prolongar la atención sobre los distintos avatares cinematográficos que siguen multiplicándose incesantemente hasta hoy. Remitimos al respecto a los muy informados volúmenes elaborados por la especialista Carolyn Joan S. Picart $(2001,2003)$. En su lugar agregaremos dos formas de proliferación de la historia y criatura en soportes y medios a menudo no considerados por pertenecer a ciertos sectores calificados desde- ñosamente como subliteratura, como lo son las publicaciones sobre el mundo cinematográfico destinadas a fans, o el universo del comic, notablemente sensibles a la impronta frankensteiniana. Así, publicaciones como Famous Monsters of Filmland, iniciada en 1958 por el mítico autor y editor Forest J. Ackerman fue un modelo replicado por numerosas revistas para el fandom editadas en América, Europa y Oriente, propagando el influjo de Frankenstein y su monstruo, entre otras entidades escalofriantes para un público que muchas veces lo llevaba a iniciáticos encuentros en tiempos de la infancia, intercalado con la visita a 
salas de cine o el encuentro en la pantalla electrónica donde los clásicos films del período sonoro encontraban reiterado y seguro lugar para su programación.

Paralelamente a la explotación de la imagen y trivia frankensteiniana en las publicaciones de fans, la industria del comic también se apropió especialmente del monstruo, convirtiéndolo por ejemplo en protagonista de sus propias aventuras como ocurre con la serie de Marvel Comics: The Monster of Frankenstein, a partir de su ingreso provocado por el escritor-editor Stan Lee, entrando y saliendo de innúmeras historias durante los años cincuenta y sesenta.

En lo que al cine toca, fue El joven Frankenstein (Mel Brooks, 1974) con su mezcla de riguroso homenaje a los films de Whale y su tratamiento humorístico pleno de guiños al público avezado fue un verdadero hito en cuanto a lectura y ampliación del universo frankensteiniano, conectándose con un goce lúdico que ya estaba presente en La novia de Frankenstein. El fenómeno se extendería en escena cuando su versión de comedia musical titulada Mel Brooks Musical Young Frankenstein se prolongó en cartel durante 2007 y 2009 . Sobre lo acontecido en los últimos años, sería extenuante una enumeración de las variaciones frankensteinanas en pantallas variadas, desde el universo del cine, la televisión y los videojuegos. Tan solo nos limitaremos a citar dos casos recientes que marcan no solo la vigencia sino la capacidad de recrear y relanzar hacia nuevas fronteras a las imágenes y las derivaciones narrativas del universo frankensteiniano. En la serie Penny Dreadful (John Logan, 2014 a la fecha) un joven Dr. Frankenstein y sus criaturas (dos masculinas y una femenina) adquieren tal relevancia que en un verdadero cónclave de monstruos victorianos no dejan de ganar espacio en cada temporada, mientras que desde la escena teatral, el cineasta escocés Danny Boyle ha dirigido a partir de la obra dramática de Nick Dear su versión de Frankenstein en una puesta de avanzada que ingresa en un espectacular territorio multimedia en cuanto a sus efectos visuales, por una parte, para ahondar en la psicología de un duelo de personajes llevados al extremos por su condición de dobles, por la otra (cabe destacar que enfatizando esta duplicidad sus dos actores protagónicos intercambian sus roles en distintos momentos de la pieza). Tanto por su dramaturgia como por su puesta en escena esta versión de Frankenstein, representada desde su première de 2011 en el National Royal Theatre londinense hasta hoy en diversas ciudades del planeta, reimagina y revitaliza una presencia intermedial que aún promete nuevos y poderosos avatares, tanto en distintas pantallas como en la pantalla interior de cada uno de sus espectadores.

Transformaciones y migraciones en la experiencia audiovisual

En tiempos del cambio de milenio, el teórico cinematográfico François Albera consideraba que la noción de intermedialidad podría brindar una clave esencial para entender los cambios acelerados que estaba ya viviendo el medio, la institución y el arte cinematográfico. Cambios que desde entonces, como puede apreciarse, no se han detenido en una nueva era de estabilización sino que se han multiplicado vertiginosamente. Albera apreciaba en las pantallas contemporáneas ciertas configuraciones, bajo la forma de películas, que parecían no responder en su estructura y funciones a las tradicionales pautas de consistencia narrativa, incluso de su diegetización sólida y envolvente. ¿Qué clase de experiencias estaban en juego allí donde no era la seducción de una historia ni la inmersión en un mundo ficcional lo que estaba en marcha, sino la participación en un devenir lúdico, de pliegues de posicionamiento dentro y fuera del film, de participación irónica o parcial y no obstante curiosamente efectiva? Algo del orden de la heterogeneidad, a veces percibida bajo el signo del pastiche y por eso mismo automáticamente adscripta a una presunta condición postmoderna, acechaba en esas películas del fin de siglo (para muchos, correlato de un necesario fin del cine tal como se lo había conocido 
durante su primera centuria). El investigador proponía estudiar este extraño fenómeno no bajo la luz de un acontecimiento completamente nuevo, sino como retorno y renovación de una vieja tradición intermedial que acompañó, aunque de una manera pulsátil, el despliegue del cine desde sus mismos inicios. (Albera, 2000, pp. 27-38)

Quince años después, el diagnóstico de Albera sigue siendo válido, y crece ante la proliferación de nuevos medios que integran hoy un sistema abierto, potenciando las clásicas posibilidades del cine y la televisión con medios digitales como las computadoras personales y las tecnologías multimedia de la movilidad (tablets, smartphones), en configuraciones transmedia que hacen de cada contacto sólo una parte, un fragmento de una experiencia en curso, que cobra su lugar y configuración, como indicaba Jürgen Muller, en el seno de interacciones (inter)mediáticas.

El acercamiento intermedial atiende la heterogeneidad constitutiva de cada medio así como las fronteras porosas entre los medios y sus estados de cambio. Este último punto resulta fundamental en un entorno donde la dinámica del cambio constante se evidencia como uno de sus atributos más sobresalientes.

Por otra parte, esta aproximación deja particularmente en evidencia las formaciones, migraciones y modos de presencia de imágenes y relatos en un entramado cultural que se hace presente en estado de proceso. Acaso las dificultades para otorgar un campo semántico estable a la noción de intermedialidad estén estrechamente relacionadas con su condición de work in progress, de idea a la que se accede en pleno desarrollo, y que se abre permanentemente a nuevos efectos de sentido en la medida en que muta el intrincado objeto al que hace referencia.

El abordaje intermedial y el aula como laboratorio

En una propuesta didáctica inscripta en el ámbito de la formación audiovisual, la atención a los aspectos intermediales de la creación de imágenes obliga a trascender cierta asentada metodología centrada en el estudio de los lenguajes particulares de cada medio, a veces relacionada con algunas ontologías particulares, que llevan a una intelección limitada de las dimensiones y fuerzas en juego. Este somero repaso del itinerario y la formación heterogénea y a la vez sincrética del mito y la figura de Frankenstein y su criatura (producciones que no sería errado calificar, a su vez, como frankensteinianas) permite no sólo apreciar los extraños derroteros por los cuales esta presencia cobró forma y expandió su poder a lo largo de los más diversos medios. Lo hizo (y sigue haciéndolo) no solamente basada en las disponibilidades más legitimadas o las más poderosas en términos de industria cultural, sino en un entramado en el que lo central y lo presuntamente marginal, lo legitimado como "alto" y lo muchas veces descartado como "bajo", concurren en la elaboración de un tejido que aún manifiesta, luego de dos siglos de recorrido, un curioso potencial, como lo demuestran los avatares contemporáneos examinados.

En síntesis, atender a lo intermedial en una propuesta educativa audiovisual implica no responder a los requisitos de búsqueda de orígenes o peor aún, al rastreo de condiciones originales de pureza para luego dejar en evidencia la degradación propia de contaminaciones varias. En resumidas cuentas, la atención a la intermedialidad permite examinar la elaboración de imágenes y relatos generados en y entre medios, e incluso off media, mediante procesos que en última instancia cabe considerar como colaborativos, construidos a la manera de un complejo bricolage por comunidades que participan de la construcción de una imagen compartida, 
cuya forma circula y en cierto modo les pertenece. De ese modo es posible encarar una enseñanza abierta a las actuales transformaciones de los medios, de las prácticas y por qué no, de las mismas imágenes creadas y compartidas por recursos diversos. Es así como se afirma como una opción altamente productiva para la apreciación e impulso de una creación audiovisual contemporánea abierta a la experimentación y la emergencia lo nuevo en un entorno medial mutante, que requiere no sólo la transmisión de saberes adquiridos sino abrir el juego a dinámicas de renovación permanente. En términos adecuadamente frankensteinianos, la incursión en los pliegues de lo intermedial inclina a convertir a la cada oportunidad de reflexión y a cada proyecto de producción audiovisual en verdaderos laboratorios operativos en el plano de la enseñanza, apelando a aquella relación dialéctica entre medios de la que hablaba el pionero Dick Higgins, donde lo previsible y programable deja lugar a la asunción de riesgos y a la bienvenida irrupción de lo inesperado.

Referencias bibliográficas

Albera, F. (2000). «Archéologie de l'intermédialité: SME/CD-ROM, l'apesanteur», Cinémas: revue d'études cinématographiques / Cinémas: Journal of Film Studies, vol. 10, n²-3, 2000, p. 27-38.

Burch, N. (1989). El tragaluz del infinito. Madrid: Cátedra.

Higgins, D. (1996). "Statement on Intermedia", en Kristine Stiles \& Peter Howard Seiz, Theories and Documents of Contemporary Art: A Sourcebook of Artist's Writings. Los Angeles, UCLA Press pp. 728-729.

Jones, S. (1994). The Illustrated Frankenstein Movie Guide. London: Titan Books.

Lecercle, J.J. (2001). Frankenstein: mito y filosofía. Buenos Aires: Nueva Visión.

Manguel, A. (1997). Bride of Frankenstein. London: British Film Institute.

Mariniello, S. (2000). "Presentation", en Cinémas: revue d'études cinématographiques / Cinémas: Journal of Film Studies, vol. 10, n² 2-3, p. 7-9 11.

Müller, J. E. (2010). "Intermediality and Media Historiography in the Digital Era", en Acta Universitatis Sapientiae, Film and Media Studies, 2, 15-38.

Petho, A. (2010). "Intermediality in Film: an Historiography of Methodologies". En Acta Universitatis Sapientiae, Film and Media Studies, 2, 39-72.

Picart, C. J. S.; Smoot; F. \& Blodget, J. (2001). The Frankenstein Film Sourcebook. London: Greenwood Publishing.

Picart, C. J. S. (2003). Remaking the Frankenstein Myth on Film. Albany: SUNY Press.

Zielinski, S. (2011). Arqueología de los medios. Hacia el tiempo profundo de la visión y la audición técnica.

Bogotá: Universidad de los Andes.

Recursos electrónicos 
Forry, S. E. (1987). "Dramatizations of Frankenstein, 1821-1986: A Comprehensive List" English Language Notes, 25:2, December, 63-79. En: Stuart Curran (ed.) Frankenstein; or, the Modern Prometheus, Pennsylvania Electronic Edition. University of Pennsylvania. Disponible en: http://knarf.english.upenn.edu/Articles/forry2.html (accedido el 13.03.2016)

\section{Abstract:}

The article proposes a revision and appropriation of the concept of intermediality, elaborated collectively within the framework of the reflection on experimental artistic practices, discourse analysis and theory, and the theory of audiovisual media. Combining different contemporary expressions on the intermedia, particularly elaborated in its relation with the theories of the cinema and the new media, examines its unfolding in the discourses and supports, considering the creation of images in their hybrid and migratory aspects as an activity modulated both between different media as within each medial structure.

In order to appreciate the heuristic and practical aspects of this approximation in its didactic potential in an area in transformation and expansion, the article studies as a symptomatic case of this modality of creation the figure and the myth of Frankenstein, along its intermedial path.

Key words: cinema - intermediality - audiovisual - teaching - experimental.

\section{Resumo:}

O artigo propõe uma revisão e apropriação do conceito de intermedialidade, elaborado de modo coletivo no marco da reflexão sobre práticas artísticas experimentais, a análise e teoria do discurso, e a teoria dos médios audiovisuais. Conjugando diferentes expressões contemporâneas sobre o intermedial, particularmente elaboradas em sua vinculação com as teorias do cinema e os new media, se examina seu desdobramento nos discursos e suportes, considerando a criação de imagens em seus aspectos híbridos e migratórios como uma atividade modulada tanto entre distintos médios como no seio de cada estrutura medial.

Para apreciar os aspectos heurísticos e práticos desta aproximação no seu potencial didá- tico num âmbito em transformação e expansão, o artigo estuda como caso sintomático dessa modalidade de criação á figura e o mito de Frankestein, ao longo do seu percurso intermedial.

Palavras chave: cinema - intermedialidade - audiovisual - ensino - experimental.

Aspectos intermediales de la enseñanza audiovisual. Un abordaje transversal, entre el cine y los nuevos medios fue publicado de la página 143 a página155 en Cuadernos del Centro de Estudios de Diseño y Comunicación Nº 